\title{
PEMBUATAN GAME PUZZLE ONLINE DENGAN PRINSIP KOOPERATIF BERBASIS ANDROID
}

\author{
1) Tofan Bimantara, ${ }^{2)}$ Sri Dianing Asri \\ ${ }^{1,2}$ )Sistem Informasi, Universitas Mercu Buana \\ 1.2)Jl. Raya Kranggan No. 6 JatisampurnaBekasi \\ E-mail : 41815210002@student.mercubuana.ac.id,dianing.asri@mercubuana.ac.id
}

\begin{abstract}
ABSTRAK
Perkembangan game online di Indonesia sangat pesat dan sangat diminati oleh banyak kalangan dari anak-anak sampai dewasa. Game online sangat digemari karena adanya sistem PVP(player vs player) dimana pemain bisa melawan pemain lain secara online. Game PVP membuat para pemainya menjadi lebih kompetitif yang memaksa pemain bermain lebih intensif agar mendapatkan level atau peringkat lebih tinggi. intensif bermain berpengaruh pada agresivitas pemain sehingga membuat perilaku kurang menghargai sesama pemain seperti mengeluarkan kata-kata makian kepada pemain lain. online juga memiliki sistem yang tidak cocok untuk anak kecil seperti adanya microtransaction dan sistem gacha. hal tersebut berakibatkan banyak anak melakukan transaksi tanpa sepengetahuan orang tuanya bahkan menghabiskan sampai puluhan juta rupiah. belum lagi sistem gacha yaitu pembelian item secara acak dimana penggunanya belum tentu mendapatkan item yang diinginkan. oleh karena itu penulis ingin membangun aplikasi game dengan prinsip kooperatif yang pantas dimainkan anak-anak. Dalam pembuatan aplikasi game "Astam Eva" ini menggunakan metode MDLC(Multimedia Development Life Cycle). MDLC sendiri memiliki tahapan-tahapan yaitu Concept, Design, Material Collecting, Assembly, Testing, dan Distribution
\end{abstract}

Kata Kunci : Kooperatif, , Puzzle, game, sistem gacha

\section{ABSTRACT}

The growth of online s in Indonesia is fast and is in great demand by many people from children to adults. Online $s$ are very popular because of the PVP system (player vs. player) that let players can fight each other online. PVP $s$ make their customers more competitive and makes players to play more intensively in order to get a higher level or ranking than other player. Playing intensively has an effect on the aggressiveness of players so that behavior makes it less respectful to other player such as issuing invective words to other players. Online s also have systems that are not suitable for kids such as microtransaction and gacha systems. this resulted in kids making transactions without the knowledge of their parents even spending up to tens millions rupiah. not to mention the gacha system, which is the purchase of items at. therefore the author wants to build a application with cooperative principles as a that deserves to be played by kids. In making this Astan Eva application using the MDLC method (Multimedia Development Life Cycle). MDLC has stages by Concept, Design, Material Collecting, Assembly, Testing, and Distribution.

Keyword: Cooperative, , Puzzle, game, gacha system

\section{PENDAHULUAN}

merupakan kegiatan yang melibatkan keputusan pemain, berupaya mencapai tujuan dengan dibatasi oleh konteks tertentu, misalnya Peraturan (Clark C. Abt 1970). Seiring perkembangan zaman bentuk game menjadi lebih modern dengan menggunakan perangkat elektronik seperti console, $P c$, atau mobile. Kelebihan dari mobile adalah bisa dimainkan dimana saja, kapanpun dan mudah diakses oleh siapa saja bahkan anak dibawah umur. Ada banyak jenis yang ada salah satumya puzzle, yaitu yang mewarkan teka-teki sebagai bagian play utamanya. puzzle bukan hanya menyusun tapi juga game memecahkan masalah berdasarkan aturan yang ada.

Sebuah permainan pada android device yang dimainkan oleh minimal dan maksimal 2 orang. ini dibuat dengan sistem online pada permainannya. Mengunakan tools Photon Unity Network yaitu sebuah package untuk multiplayer online.

Belakangan ini industri game sangat 
berkembang pesat khususnya game android. Saat ini telah bermunculan game-game android dengan visualisasi yang bagus dan fitur-fitur yang unik. Pada game ini dua pemain harus bekerja sama dalam memecahkan teka-teki yang ada pada setiap level. Masing-masing pemain memiliki kemampuan yang berbedabeda.satu pemain dapat mengalahkan parah musuh akan tetapi tidak dapat menjangkau tempat-tempat yang tinggi, pemain lainmemiliki kemampuan sebaliknya. Permainan ini akan berakhir bila 2 pemain selamat sampai tujuan yaitu rumah mereka selain itu akan disediakan tempat checkpoint sebelum mencapai tujuan.

Berdasarkan uraian diatas, penulis bermaksud merancang aplikasi permainan koperatif multiplayer Online. Diharapkan game ini tidak hanya dapat menghibur juga dapat melatih kemampuan kerjasama anak.

1. Rumusan masalah

Berdasarkan latar belakang, dapat dirumuskan permasalahannya adalah bagaimana membuat game kooperatif online yang baik bagi anak dan dapat meningkatkan kemampuan kerja sama dalam tim/kelompok?

\section{Batasan Masalah}

Batasan masalah yang dimiliki, yaitu:

- Game hanya dapat dimainkan oleh maksimal dan minimum 2 orang (CO-OP).

- Game hanya dapat dimainkan bila terhunung koneksi internet.

- Target pemain adalah pra-remaja umur 7-13 tahun.

- Game dirancang dalam dua dimensi (2D).

- Menggunakan perangkat lunak Unity sebagai Game engine.

- Menggunakan bahasa pemrograman C\#.

- Hasil game yang telah selesai dirancang untuk dapat dimainkan pada perangkat mobile bersistem operasi android.

\section{Pengertian Game}

Game atau permainan adalah sesuatu yang dapat dimainkan dengan aturan tertentu sehingga ada yang menang dan ada yang kalah, biasanya dalam konteks tidak serius atau dengan tujuan refreshing.[17]. Game dapat membangan otak, untuk meningkatkan konsentrasi dan melatih untuk memecahkan masalah dengan tepat dan cepat.[1]

\section{Jenis Game}

Jenis-jenis dan genre game merupakan dua hal yang berbeda pada games. Jenis game merupakan jenis gameplay pada game sedangkan genre merupakan diskripsi pada cerita yang ada didalam game.

Berikut adalah jenis games.

1. Action

Action game adalah game yang menawarkan secara intensif hal yang berbauaction sebagai bagian utama game. Gerakan refleks yang bagus sangat diperlukan pada game jenis ini. Action game biasanya sebuah game shooters, stealth, atau game olahraga.

\section{Adventure}

Game yang menawarkan eksplorasi dan pemecahan masalah sebagai bagian utama games. Penalaran, kekreatifan ,dan rasa ingin tahu yang tinggi adalah kemampuan yang dibutuhkan pada game jenis ini.

\section{Puzzle}

Puzzle game adalah game yang mewarkan teka-teki sebagai bagian utama gameplaynya.game puzzle bukan hanya game menyusun tapi juga game memecahkan masalah berdasarkan aturan yang ada.

\section{Role Playing}

Game yang menawarkan persaan seperti berada pada situasi karakter yang ada dalam game. Game jenis ini biasanya memiliki 
kekayaan cerita dan pendalaman karakter sehingga pemain ikut terbawa dalam suasana.

\section{Simulation}

Game ini merupakan simulasi dari keadaan asli yang ada didunia nyata. Ada beberapa pembagian game simulasi antara lain game simulasi manusia seperti The SIMS.

\section{Strategy}

Strategy game adalah game yang menawarkan penalaran dan pememcahan masalah. Game jenis ini biasanya tidak banyak storytelling didalamnya agar pemain dapat memahami sendiri dan membentuk strategi sendiri.

\section{Game Genre}

genre adalah menjelaskan bagaimana cerita dalam gamediceritakkan. Sebuah genre adalah gaya bercerita yang berpengaruh pada struktur cerita, pendalamaan karakter, dan element storytelling lainya.

Pada dasarnya genre sama seperti genre pada filmatau acara TV lainya. Berikut adalah macam genrenya: [2]

\section{Online Multiplayer Game}

Online multiplayer game adalah permainan game yang terhubung dengan jaringan internet. Ada banyak tools untuk membuat game online salah satunya PUN(Photon Unity Networking ). PUN memiliki kelebihan yaitu:

1. Pencarian permainan yang fleksible

2. Mudah digunakan

3. Dapat digunakan secara gratis. [3]

\section{Game Engine dan bahasa pemrograman}

- Game Engine

Mungkin kalian pernah dengar istilah "Game Engine" sebelumnya Tetapi kurang mengerti istilah tersebut.Game engine adalah arsitektur yang digunakan depeloper sebagai alat untuk membuat game. [4]

\section{- Unity}

Salah satu game engine yang ada adalah Unity.Unity merupakan game engine multiplatform.Unity mampu di publish menjadi Standalone (.exe), berbasiskanweb, Android, IoS, Iphone, XBOX, dan lain-laim. Salah satu keunggulan dari unity adalah adanya personal edition yang mana gratis digunakan oleh semua orang.Unity juga memiliki professional edition yang diharuskan membayar iuran per-bulan dan memiliki tools tambahan yang tidak bisa diakses pada personal edition.[5]

- C Sharp

C Sharp adalah bahasa pemrograman baru yang diciptakan oleh Microsoft yang dikembangkan di bawah kepemimpinan Anders Hejlsberg yang telah menciptakan berbagai macam bahasa pemrograman termasuk Borland Turbo $\mathrm{C}++$ dan orland Delphi.Bahasa C\# juga telah di standarisasi secara internasional oleh ECMA. Seperti halnya bahasa pemrograman yang lain, C\# bisa digunakan untuk membangun berbagai macam jenis aplikasi, seperti aplikasi berbasis windows (desktop) dan aplikasi berbasis web serta aplikasi berbasis web service. [6]

\section{Database}

Pengertian database adalah suatu kumpulan data terhubung yang disimpan secara bersama-sama pada suatu media, tanpa mengatap satu sama lain atau kerangkapaan data, data disimpat dengan cara-cara tertentu agar mudah digunakan atau ditampilkan kembali; data dapat digunakan oleh satu atau lebih program aplikasi; dan dapat disimpan tanpa ketergantungan dengan program lain; data disimpat sedemikian rupa agar mudah untuk diatur.[7] 


\section{- SQLite}

SQLite adalah database yang tertanam jadi SQLite berdiri sendiri tanpa perlu server proses terpisah tapi membaca dan menulis langsung pada file disknya.SQLite juga termasuk open source karena gertis digunakan untuk tujuan pribadi maupun komersial.[8]

\section{Penelitian Terkait}

- Penelitian yang dilakukan oleh Fajar Masya, Budi Aryadi, 2009, "Permainan 2 Player Gaza Wars pada Jaringan Lokal". Latar belakang pada penelitian ini yaitu peneliti bermaksud merancang sebuah aplikasi permainan 2 player yang dapat dimainkan pada sebuah jaringan lokal.Kesimpulan yang diambil adalah aplikasi permainan ini memungkinkan pemakai komputer untuk memainkan permainan Gaza Wars in tanpa harus berhadapan secara langsung. Dalam aplikasi permainan ini setiap skor akan disimpan dalam database dan peringkat skor pemain tertinggi akan ditampilkan dalam form high score. Perangkat lunak yang digunakan dalam pembuatan aplikasi permainan ini adalah menggunakan model build and fix.[9]

- Penelitian yang dilakukan oleh Fajar Masya, Elvina, 2010, "Pengembangan Aplikasi Permainan Scrabble Dua Bahasa Menggunakan Java". Rumusan masalah pada penelitian ini yaitu bagaimana mengembangkan permainan scrabble yang memiliki kamus permainan dalam Bahasa Indonesia dan mengimplementasikan ke dalam suatu aplikasi untuk personal komputer (PC). Kesimpulannya adalah dengan menggunakan metode rekayasa perangkat lunak waterfall, pada tahap analisis masalah maka diperoleh model permasalahan pada Aplikasi ini.Metode pengujian yang digunakan adalah metode black box dan white box.Aplikasi Permainan Scrabble dua bahasa ini telah dapat dimainkan selayaknya seperti scrabble biasa.[10]

- Penelitian yang dilakukan oleh Kresno
Murti Mulyono, Hanif Al Fatta, 2012, "Pembuatan Game Labirin Dengan Menggunakan Blender 3D". Kesimpulan yang diambil adalah peneliti bermaksud merancang game labirin dengan menggunakan Blender 3D. Metode Penelitian yang dilakukan adalah Analisis, Persiapan dalam Penelitian, Perancangan Antarmuka, lalu Perancangan Game. Aplikasi Game Labirin ini dapat dimainkan pada komputer dengan dimasukkan kedalam CD.[11]

- Penelitian yang dilakukan oleh Wahyu Pratama, 2014," Game Adventure Misteri Kotak Pandora ". Latar belakang pada penelitian ini yaitu game ini dapat menjadi salah satu bentuk usaha memajukan dan ikut berpartisipasi dalam dunia game khususnya di Indonesia, dengan latar belakang tempat yang mempunyai unsur budaya Indonesia seperti adanya candi dalam latar belakang tempat pada game ini. Rumusan masalah pada penelitian ini yaitu bagaimana membuat "Game Adventure Misteri Kotak Pandora" sebagai salah satu bentuk usaha memajukan dan ikut berpartisipasi dalam dunia game khususnya di Indonesia. Metode penelitian yang digunakan adalah metode Multimedia Development Life Cycle (MDLC).Metode pengujian yang digunakan adalah metode black box testing dan kuesioner.[12]

- Penelitian yang dilakukan oleh Yeti Ekasari,2012,"Merancang Game Petualangan "Binggo" menggunakan Unity 3D Game Engine". Kebutuhan sistem fungsional game binggo yaitu sistem harus dapat mengatur audio yang dibutuhkan oleh pengguna, sistem harus dapat memproses AI(Artificial Intelligence) yang ada dalam game seperti menghitung point yang ditentukan sehingga dapat menyelesaikan misi, sistem dapat memberikan informasi mengenai cara bermain dalam game binggo. 
Kesimpulan dari game Binggo yaitu membuat game yang menarik itu tidak sulit dengan menggunakan Unity 3D Game Engine dan unity 3D game engine mudah untuk dipelajari bagi pemula maupun profesional.[13]

- $\quad$ Penelitian yang dilakukan oleh Agung Pamungkas, Eka Puji Widiyanto, dan Renni Angreni, 2014, " Penerapan Algoritma A* ( A Star ) Pada Game Edukasi The Maze Island Berbasis Android ". Latar belakang pada penelitian ini adalah untuk menerapkan algoritma $A^{*}$ ( A Star ) dalam penyelesaian permainan The Maze Island berbasi Android. Metode yang digunakan oleh penulis adalah metode Prototyping dengan tahap-tahapan seperti perencanaan, mendesain, evaluasi desain, membangun sistem, menguji sistem, dan implementasi sistem. Penggunaan Algoritma $A^{*}$ dikarenakan algoritma ini memiliki nilai heuristic sebagai nilai pembanding sehingga dapat mencari solusi yang terbaik dari permasalahan yang ada jika solusi itu memang ada.[14]

- Penelitian yang dilakukan oleh Muhammad Rizky Rahadi, Kodrat Imam Satoto, 2016," Perancangan game math adventure sebagai media pembelajaran matematika berbasis android". Tujuan dari penelitian ini upaya meningkatkan efisiensi penyediaan aplikasi yang mengandung unsur pendidikan diperlukan inovasi baru yaitu game edukasi matematika yang diharapkan membantu proses pembelajaran matematika dan menghilangkan rasa jenuh dan takut bagi anak-anak untuk belajar matematika. Metodologi yang digunakan dalam penelitian ini adalah Multimedia Development Life Cycle (MDLC). Kesimpulan Aplikasi Math Adventure telah berjalan sesuai dengan fungsinya.[15]

- Penelitian yang dilakukan oleh Meiki Kurniawan dan Fithri Selva Jumeilah, 2015, “ Penerapan Algoritma Depth-First Search
Sebagai Maze Generator pada Game Labirin Menggunakan Unity 3D ". Tujuan penelitian ini yaitu penulis ingin menerapkan algoritma Depth-first search supaya pemain tidak terlalu banyak memasuki ruangan buntu yang akan menyulitkan pemain tersebut, serta menambahkan materi pembelajaran tentang fase - fase metamorphosis hewan untuk anak - anak sekolah dasar. Metode penelitian yang digunakan adalah metode prototyping.Hasil dari pengujian, penerapan algoritma Depth-First Search dapat membangkitkan labirin setiap kali permainan dimulai serta bentuk labirin yang diciptakan sudah sesuai dengan kriteria labirin sempurna. [16]

- Penelitian yang dilakukan oleh Graficha Aryudhetika Kusuma dan Endah Sudarmilah, 2016, “ Pengembangan Permainan Labirin untuk Membantu Perkembangan Motorik Anak ". Pada penelitian ini penulis bertujuan membuat game untuk membantu mengembangkan motorik halus yang berkaitan dengan kecerdasan dan perkembangan visual motor yang merupakan indikator yang baik pada anak. Metode penelitian yang digunakan adalah System Development Life Cycle ( SDLC ).Metode pengujian yang digunakan adalah Black Box testing. Dari hasil penelitian, aplikasi ini akan membantu minat anak dalam belajar maze.[17]

- Penelitian yang dilakukan oleh Muhammad Abdul Basith Asyakur, 2017, “ Hubungan Antara Intensitas Bermain Game Online Dengan Kecenderungan Agresivitas Pada Komunitas Gaming Surabaya ". Penelitian ini didasari pada tingginya peminat game online pada anak muda/komunitas di Surabaya. Hasil dari analisa peneliti yaitu adanya hubungan yang positif dengan intensitas bermain game online yang ditunjukan pada anggota komunitas gaming Surabaya berjalan searah 
dengan tingginya tingkat kecenderungan agresivitas pada anggota komunitas gaming Surabaya. Hal ini disebabkan oleh game kompetitif yang memaksa pemainya semakin tinggi frekuensi dan lama waktu seseorang bermain game online, maka peluang untuk munculnya kekalahan dan hambatan semakin tinggi. [18]

\section{METODE}

\section{Teknik Pengumpulan Data}

Teknik pengumpulan data yang dilakukan dalam penelitian ini adalah

- Studi Pustaka

Mencari sumber buku, artikel, dan literatur internet yang berhubungan dengan topik penelitian. kemudian mempelajari dan memahami materi tersebut sebagai penunjang dalam penelitian.

\section{Diagram Alir Penelitian}

Dalam pembuatan aplikasi game Maze Hunter ini menggunakan metode MDLC(multimedia Development Life Cycle). MDLC sendiri memiliki tahapan-tahapan yaitu:

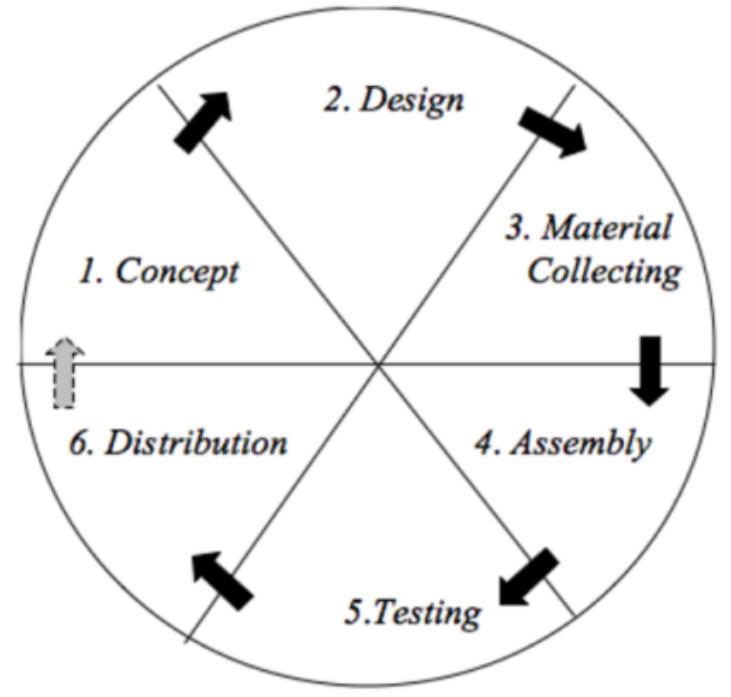

Gambar 1. MDLC

\section{Concept}

Membuat konsep game yang akan dibuat dari mulai tema, tujuan, target pengguna, tujuan game, dan spesifikasi umum.

\section{Design}

Pada tahap ini membuat spesifikasi secara rinci mengenai arsitektur program Di mana pembuatannya disesuaikan berdasarkan pada Flowchart.

\section{Material Collecting}

Pengumpulan bahan yang sesuai dengan kebutuhan yang dikerjakan.bahan tersebut antara lain foto, audio, font, dan 2D karakter

\section{Assembly}

Tahap dimana semua objek atau bahan multimedia dibuat.Pembuatan aplikasi didasarkan pada flowchart.Semua objek atau material dibuat dan digabungkan menjadi satu aplikasi yang utuh.

\section{Testing}

pengujian, baik tahap alfa maupun beta dan langsung memperbaiki jika terdapat bug atau error.

\section{Distribution}

Dalam tahapan ini, aplikasi yang telah selesai diuji dan dinyatakan baik sesuai dengan tujuan pembuatan, akan didistribusikan kepada target pengguna sesuai yang ditentukan pada concept.

HASIL

Concept

\section{Skenario Permainan}

- Tahap awal permainan ini adalah dengan menampilkan menu utama. Pemain menekan tombol $\angle O B B Y$ untuk masuk kedalam halaman lobby - Pada tampilan tersebut juga terdapat tombol lain yaitu $H I G H$ SCORE untuk melihat 5 pemain score tertinggi, EXIT untuk keluar dari permainan.

- Pada halaman Lobby terdapat 2 textfiled, satu tombol yaitu tombol CREATE ROOM dan daftar room yang telah dibuat. Pemain sebagai client dapat membuat room 
permainan dengan memasukan nama room, nama Pemain lalu menekan tombol CREATE ROOM jika berhasil maka pemian berada di dalam room yang telah dibuat. Pemain lain menekan tombol room yang mucul untuk masuk ke dalam room yang sudah dibuat oleh pemain lain jika berhasil pemain masuk ke dalam room.

- Di dalam room ter dapat 2 tombol yaitu tombol START dan LEAVE ROOM lalu terdapat daftar pemain yang masuk ke dalam room. Maksimal pemain yang masuk hanya 2 pemain dan hanya dapat memulai permainan jika terdapat 2 pemain. Tekan tombol START untuk masuk kedalam LEVEL SELECTION. Tombol LEAVE untuk keluar room.

- Didalam LEVEL SELECTION terdapat pilihan level dan tekan pilihan level yang diinginkan.

- Didalam permaianan terdapat 2 karakter pemain yaitu elang dan rubah. Room master menggunakan rubah dan pemain lain menggunakan elang. Kontrol dalam permainan pun berbeda rubah memiliki virtual joy stick untuk bergerak dan tombol LOMPAT untuk lompat sedangkan elang hanya menggunkan virtual joy stick. Rubah dapat mengalahkan musuh dengan cara melompat lalu mendarat diatas musuh sedangkan elang dapat terbang.

- Semakin cepat menyelesaikan permainan dan banyak mengumpilkan coin maka, semakin tinggi score yang didapat dalam permainan.

- Jumlah level pada permainan 5, termasuk 1 level untuk tutorial.
- Permainan berakhir bila semua pemain selamat mencapai tujuan.

- Ketika pemian kehabisan nyawa makan permainan over.

\section{Spesifikasi kebutuhan game}

1. Element permainan terdiri dari :
A. Gambar latar belakang permainan
B. Gambar 2 karakter pemain
C. Efek suara
D. Gambar virtual joystick dan tombol
E. Gambar stageplatform
F. Animasi karakter

2. Proses penghitungan score:
A. Score didapat berdasarkan waktu menyelesaikan tiap level, semakin cepat semakin tinggi score yang didapat.
B. Akan ada tambahan score bila mendapatkan koin. Semakin banyak koin semaki besar score yang didapat

3. Aplikasi permainan menggunakan Touchcontrols untuk mengontrol dan mengendalikan karakter masingmasing pemain.

4. Saling membatu dalam memecahkan yang ada masalah di setiap level.

\section{Design}

Berikut adalah perancangan user interface atau antar muka yang bertujuan untuk mempermudah penggambaran dari story board secara menyeluruh. 
Table 1. Table Design Antar Muka Aplikasi

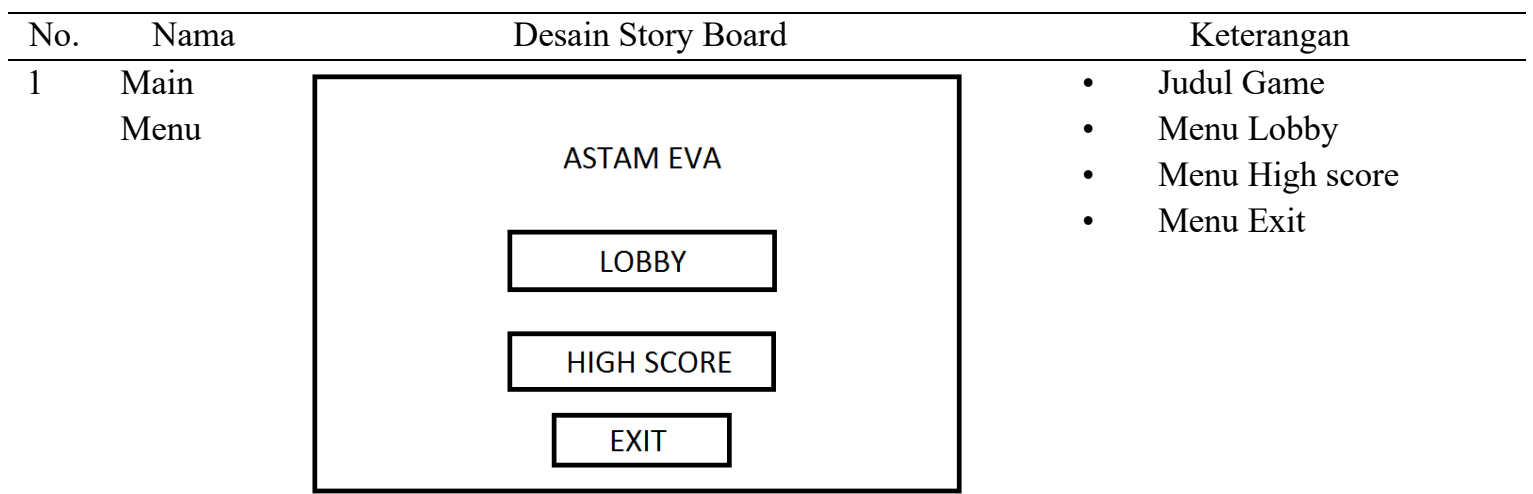

Gambar 2. Antar Muka MainMenu

2 High

Score

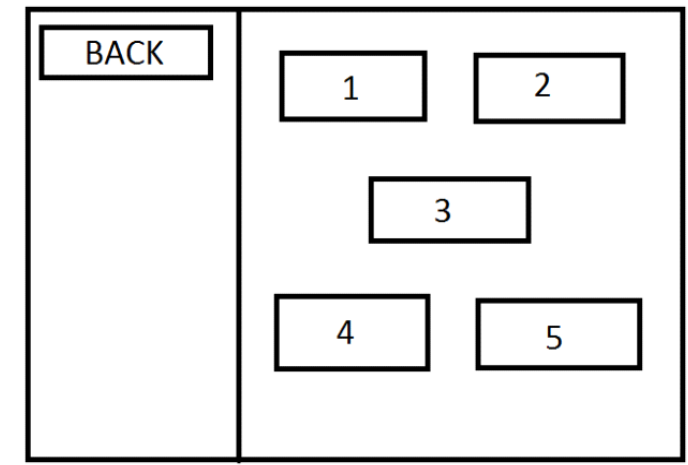

Gambar 3. Antar Muka Pilih Level High Score

\begin{tabular}{|l|l|l|}
\hline \multicolumn{3}{|c|}{ SCORE LEVEL } \\
NO & NAMA & SCORE \\
\hline
\end{tabular}

BACK

Gambar 4. Antar Muka High Score

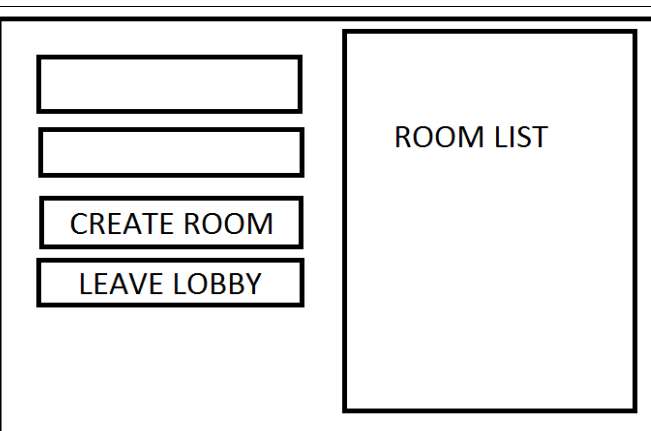

- Tampilan 3 score tertinggi perlevel

Gambar 5. Antar Muka Lobby 


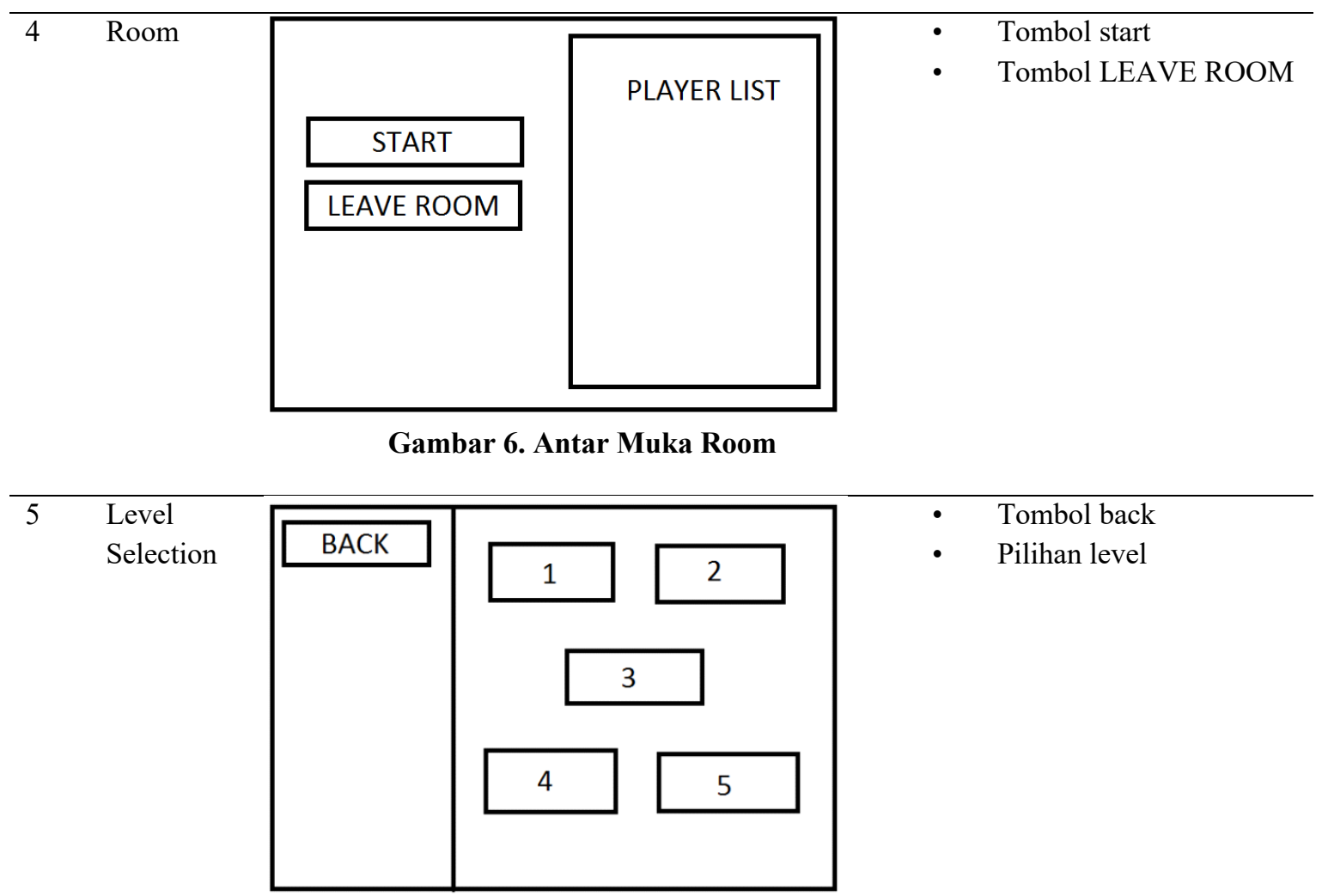

Gambar 7. Antar Muka Pilih Level

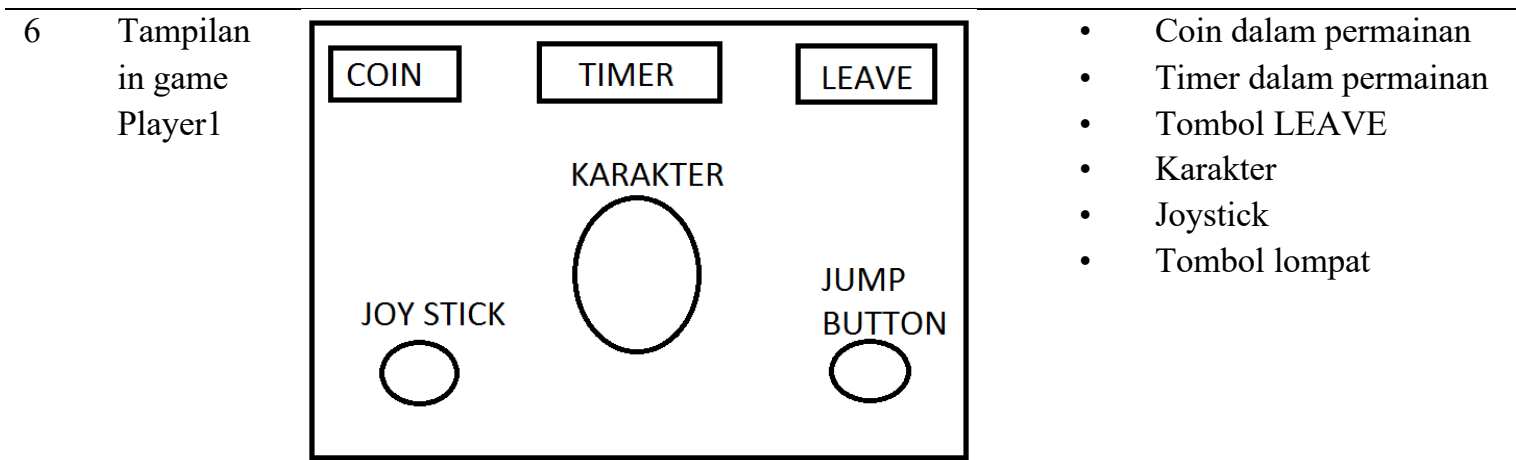

Gambar 8. Antar Muka Gameplay Player 1

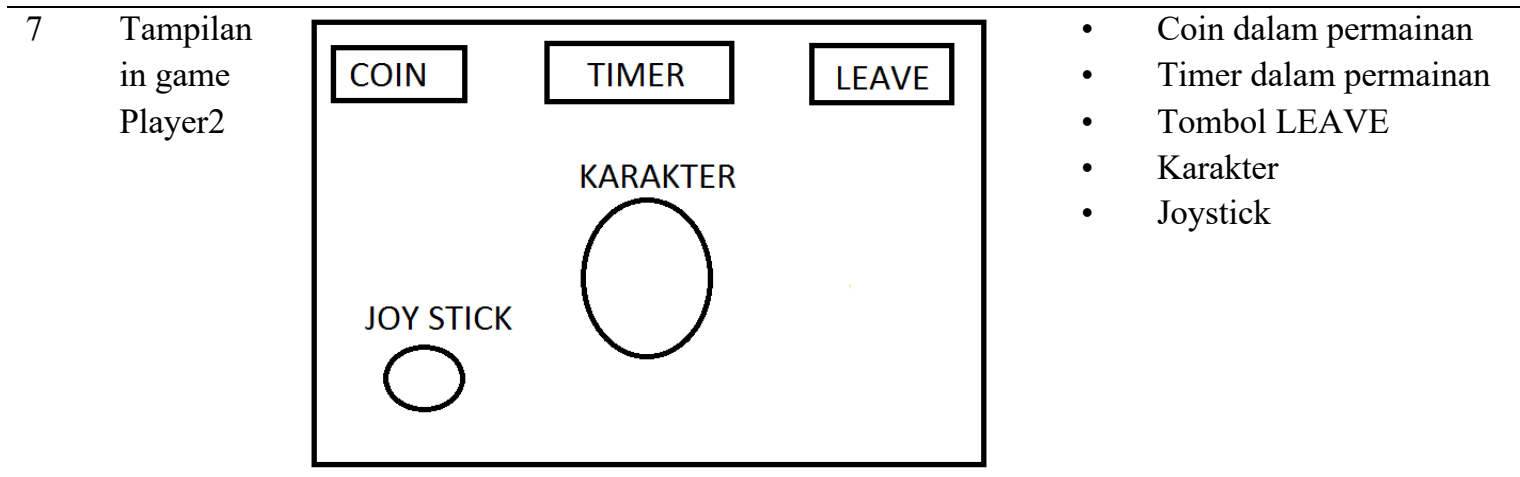

Gambar 9. Antar Muka Gameplay Player 


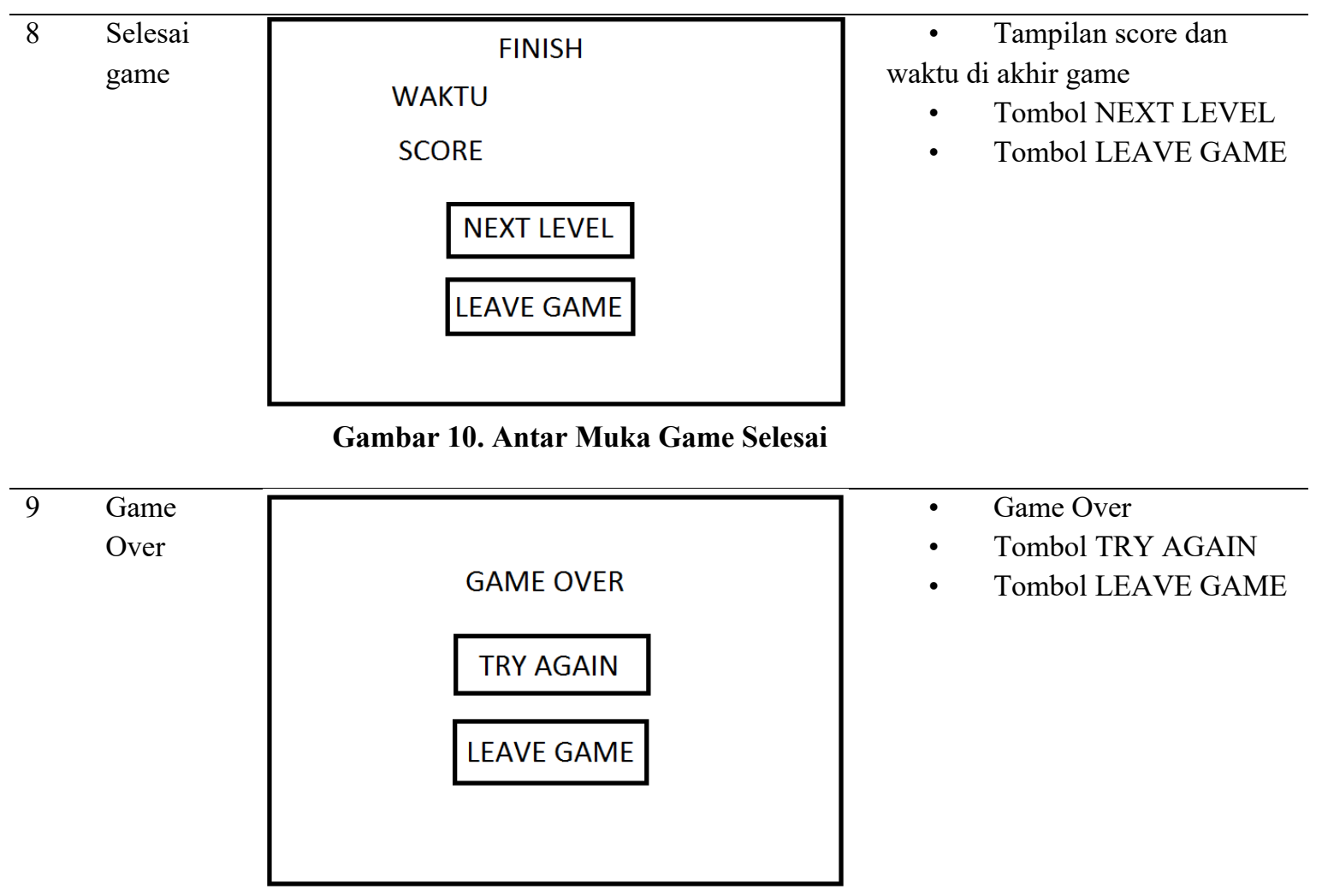

Gambar 11. Antar Muka Game Over

\section{Material Collection}

Merupakan proses untuk pengumpulan segala sesuatu yang dibutuhkan dalam proyek. Untuk penggunaan audio dan asset game penulis akan menggunakan audio dan asset game dengan lisensi gratis untuk dipasang pada game ini.

\section{Assembly}

1. Tampilan Main Menu

Main Menu merupakan halaman utama dari permainan ini. Pada menu ini terdapat tomboltombol yaitu LOBBY, HIGH SCORE, dan EXIT. Tombol Lobby untuk pergi lobby game, High score untuk ke halamn high score dan exit untuk menutup aplikasi.

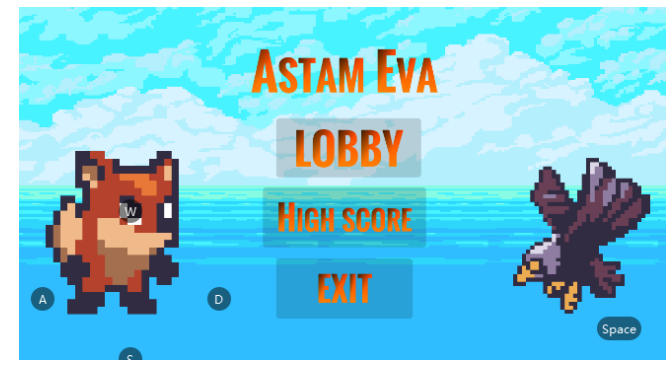

Gambar 12. Implementasi Main Menu

2. Tampilan high score

Tampilan ini menampilkan 3 score tertinggi berdasarkan level. Level dapat dipilih level mana yang ingin diketahui high scorenya. 


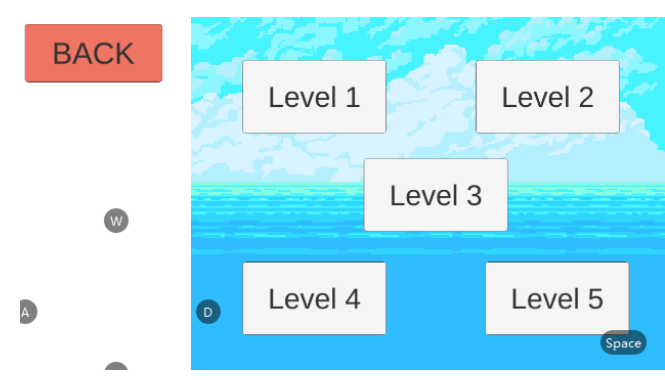

Gambar 13. Implementasi Pilih Level High Score

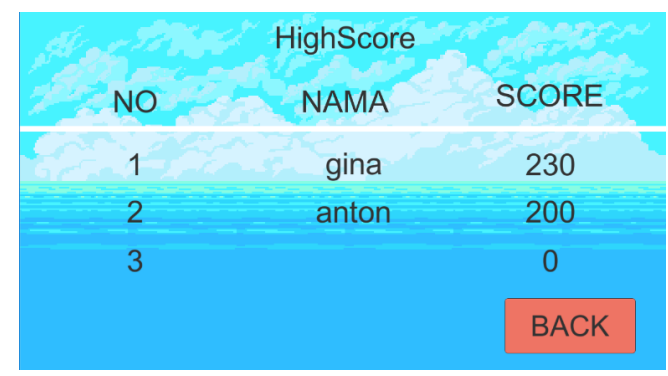

Gambar 14. Omplementasi High Score

3. Tampilan Lobby

Tampilan lobby menampilkan room yang sudah di buat. Pada lobby juga ter dapat tombol make room untuk membuat room. Leave lobby untuk kembali ke main menu.

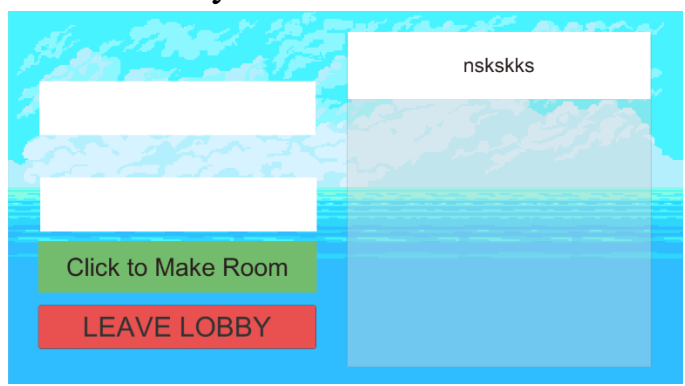

Gambar 15. Implementasi Room

4. Tampilan Room

Tampilan room terbuat bila pemain telah masuk ke dalam room. Terdapat daftar pemain yang sudah masuk room. Start match untuk ke halaman pilih level. Leave room untuk meinggalkan room.

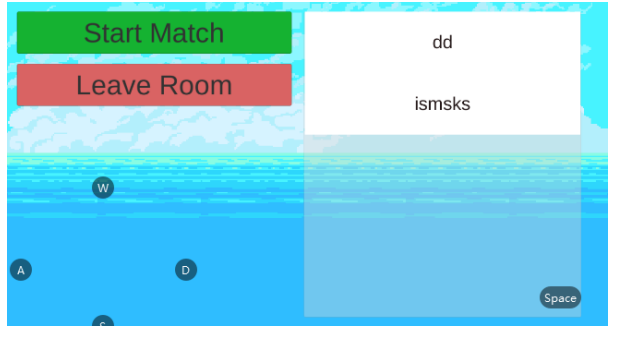

Gambar 16. Implementasi Room

5. Tampilan pilih level

Tampilan pilih level menampilkan pilihan level yang dapat dimainkan.

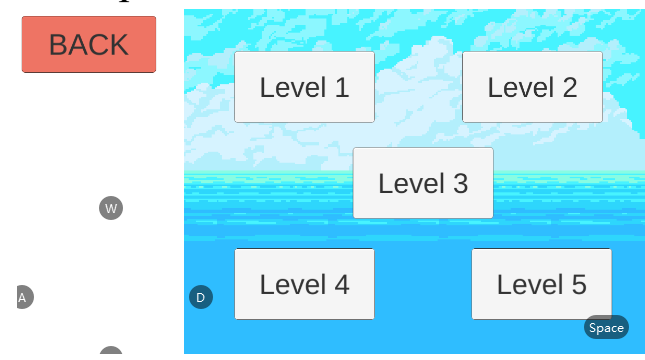

Gambar 17 Implementasi Pilih Level

6. Tampilan gameplay

- Player 1

Setelah memilih level pemain masuk ke dalam bagian gameplay. Pada gameplay level 1 pemain dimuculkan di dalam sebuah area dan bertujuan untuk menemukan jalan pulang ke rumah dengan memecahkan rintangan.

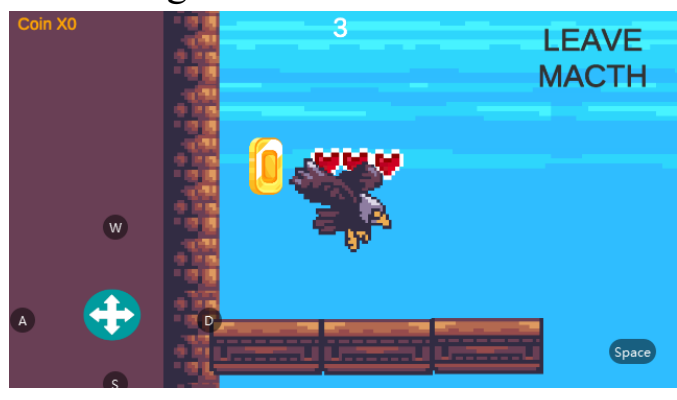

- $\quad$ Player 2 


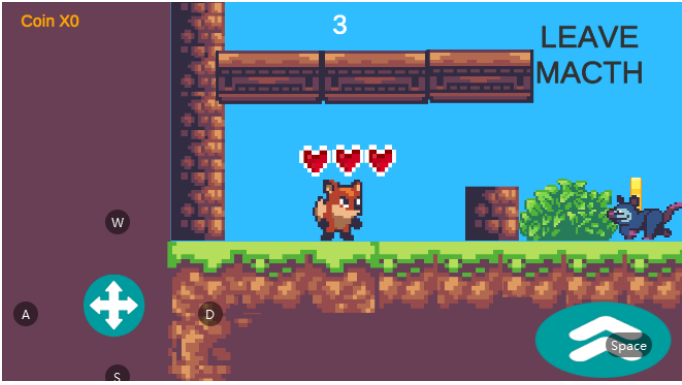

7. Tampilan gameover

Tampilan ini muncul ketika salah satu pemain kehabisan nyawa. Dalam tampilan ini terdapat 2 tombol TRY AGAIN untuk mengulang level sedangkan LEAVE GAME untuk meninggalkan permainan.

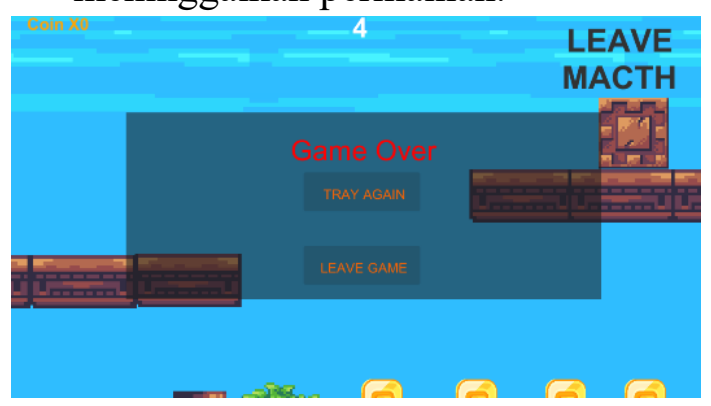

Gambar 18 Implementasi Game Selesai
8. Tampilan selesai game

Game selesai apa bila pemain sampai tujuan dan tidak kehabisan nyawa. Pada tampilan ini terdapat 2 tombol NEXT LEVEL untuk ke menu pilih level sedangkan LEAVE GAME untuk meninggalkan game.

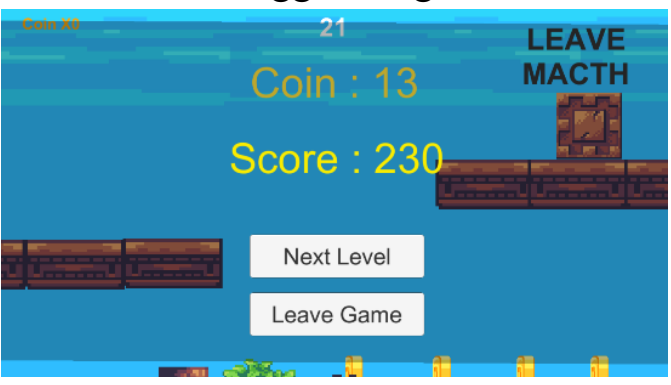

\section{Testing}

Pengujian game dilakukan dengan metode Black-Box yaitu pengujian dimana penilaian terhadap aplikasi terletak pada fuctionalitasnya. Pengujian akan disajikan berupa table.

Table 2. Table Testing Aplikasi

\begin{tabular}{lllll}
\hline No & Kasus & Skenario pengujian & $\begin{array}{l}\text { Hasil yang } \\
\text { diharapkan }\end{array}$ & Status \\
\hline 1 & Buat Room & $\begin{array}{l}\text { Pilih buat room tanpa } \\
\text { mengisi nama pemain dan } \\
\text { nama room }\end{array}$ & $\begin{array}{l}\text { Menampilkan } \\
\text { peringatan isi nama } \\
\text { pemain dan nama } \\
\text { room }\end{array}$ & Berhasil \\
& & Menampilkan & Berhasil \\
& Pilih buat room tanpa & peringatan isi nama & \\
& mengisi nama pemain & pemain & \\
& & Menampilkan & Berhasil \\
& Pilih buat room tanpa & peringatan nama & \\
& mengisi nama room & &
\end{tabular}




\begin{tabular}{|c|c|c|c|c|}
\hline & & $\begin{array}{l}\text { Pilih buat room mengisi } \\
\text { nama pemain dan nama } \\
\text { room }\end{array}$ & Berhasil buat room & Berhasil \\
\hline \multirow[t]{2}{*}{2} & $\begin{array}{l}\text { Bergabung } \\
\text { kedalam } \\
\text { room }\end{array}$ & $\begin{array}{l}\text { Pilih room yang ada tanpa } \\
\text { mengisi nama pemain }\end{array}$ & $\begin{array}{l}\text { Menampilkan } \\
\text { peringatan isi nama } \\
\text { pemain }\end{array}$ & Berhasil \\
\hline & & $\begin{array}{l}\text { Pilih room yang ada dan } \\
\text { mengisi nama pemain }\end{array}$ & $\begin{array}{l}\text { Berhasil bergabung } \\
\text { dalam room }\end{array}$ & Berhasil \\
\hline \multirow[t]{2}{*}{3} & $\begin{array}{l}\text { Memulai } \\
\text { permainan }\end{array}$ & $\begin{array}{l}\text { Pilih start match dengan } \\
\text { hanya ada satu pemain }\end{array}$ & $\begin{array}{l}\text { Menampilkan } \\
\text { peringatan harus } \\
\text { lebih dari satu } \\
\text { pemain }\end{array}$ & Berhasil \\
\hline & & $\begin{array}{l}\text { Pilih start match dengan } \\
\text { lebih dsri satu pemain }\end{array}$ & $\begin{array}{l}\text { Berhasil } \\
\text { menampilkan } \\
\text { halaman pilih level }\end{array}$ & Berhasil \\
\hline 4 & Bergerak & $\begin{array}{l}\text { Pemain mengerakan } \\
\text { virtual joy stick }\end{array}$ & $\begin{array}{l}\text { Berhasil } \\
\text { mengerakan karakter }\end{array}$ & Berhasil \\
\hline 5 & $\begin{array}{l}\text { Mengambil } \\
\text { coin }\end{array}$ & $\begin{array}{l}\text { Pemain mengerakan } \\
\text { karakter mengenai coin }\end{array}$ & $\begin{array}{l}\text { System } \\
\text { menambahkan } \\
\text { jumlah coin }\end{array}$ & Berhasil \\
\hline 6 & $\begin{array}{l}\text { Mengalahkan } \\
\text { musuh }\end{array}$ & $\begin{array}{l}\text { Pemain mengerakan } \\
\text { karakter mengijak mush }\end{array}$ & $\begin{array}{l}\text { System } \\
\text { menghilangkan } \\
\text { mush }\end{array}$ & Berhasil \\
\hline 7 & $\begin{array}{l}\text { Mendorong } \\
\text { benda }\end{array}$ & $\begin{array}{l}\text { Pemain mengerakan } \\
\text { karakter mengenai benda }\end{array}$ & $\begin{array}{l}\text { System mengerakan } \\
\text { benda }\end{array}$ & Berhasil \\
\hline 8 & High Score & Pilih menu high score & $\begin{array}{l}\text { System } \\
\text { menampilkan } 3 \\
\text { score terbesar } \\
\text { perlevel }\end{array}$ & Berhasil \\
\hline
\end{tabular}

\section{KESIMPULAN}

Berdasarkan analisa akhir penulis 2. Dalam hasil evaluasi diatas penulis terhadap pembuatan game "Astam Eva" dapat kesimpulan sebagai berikut: dapat menyimpulkan bahwa telah berhasil membuat game puzzle yang

1.Game ini telah berhasil membuat koneksi mampu meningkatkan kemampun kerja multiplayer melalui jaringan internet. sama pemain 


\section{DAFTAR PUSTAKA}

[1] M. Fikri, "Rancangan Bangun Aplikasi Game Battleship Multiplayer pada Jaringan LAN," p. 95, 2013.

[2] L. Grace, "Game Type and Game Genre Game Type," 2005.

[3] Photon, "Introduction." [Online]. Available:

https://doc.photonengine.com/enus/pun/current/getting-started/pun-intro.

[4] G. Designing, "The Top 10 Video Game Engine." [Online]. Available: https://www.gamedesigning.org/career/ video-game-engines.

[5] Unity, "The world's leading real-time creation platform." [Online]. Available: https://unity3d.com/unity/.

[6] T. Ponit, "C\# Tutorial." [Online]. Available: https://www.tutorialspoint.com/csharp/.

[7] S. E., Basis Data Dalam Tinjauan Konseptual. 2011.

[8] Sqlite, “About Sqlite." [Online]. Available:

https://www.sqlite.org/about.html.

[9] F. Masya and B. Aryadi, "Permainan 2 Player Gaza Wars pada Jaringan Lokal," vol. III, no. 1, pp. 70-77, 2011.

[10] F. Masya and ; Elvina, "Pengembangan Aplikasi Permainan Scrabble Dua Bahasa Menggunakan Java," pp. 133138, 2010.

[11] K. M. Mulyono, "Pembuatan Game Labirin Dengan Menggunakan Blender 3D," J. Dasi, vol. Volume 13, no. Nomor 2, 2012.

[12] W. Pratama, "Game Adventure Misteri Kotak Pandora," J. Telemat., vol. 7, no. 2, pp. 13-31, 2014.

[13] Y. Ekasari, "Merancang Game Petualangan 'Binggo' Menggunakan Unity 3D Game Engine," Merancang Petualangan "Binggo" Menggunakan
Unity 3D Engine, pp. 1-20, 2012.

[14] Pamungkas. dkk, "Penerapan Algoritma A* ( A Star ) Pada Game Edukasi The Maze Island Berbasis Android," Penerapan Algoritm., no. x, pp. 1-11, 2011.

[15] M. R. Rahadi, K. I. Satoto, and I. P. Windasari, "Perancangan Game Math Adventure Sebagai Media Pembelajaran Matematika Berbasis Android," J. Teknol. dan Sist. Komput., vol. 4, no. 1, p. 44, 2016.

[16] M. Kurniawan and F. S. Jumeilah, "Penerapan Algoritma Depth-First Search Sebagai Maze Generator pada Game Labirin Menggunakan Unity 3D," no. x, pp. 1-10, 2015.

[17] G. A. Kusuma and E. Sudarmilah, "Pengembangan Permainan Labirin untuk Membantu Perkembangan Motorik Anak," J. Fak. Tek. Univ. Khairun, vol. 03, no. 2354 - 8924, pp. 46-89|, 2016.

[18] M. A. B. Asyakur, "Hubungan antara Intensitas Bermain Game Online Dengan Agresifitas Pada Komunitas Gaming Surabaya" 2017. 